\title{
An Evaluation of the Impact of Food Safety Management Systems (Fsmss) Within the Wine Industry in Karnataka, India
}

\author{
Mr. Krushna Yadav D.K ${ }^{1}$, Er. R.N Shukla ${ }^{2}$, Er. A.A Mishra ${ }^{3}$, Er. A Kumar ${ }^{4}$, \\ Ms. Shilpa K ${ }^{5}$ \\ ${ }^{\text {I }}$ (Dept. of food process Engineering, Sam Higginbottom Institute of Agriculture, Technology \& Sciences, India) \\ ${ }_{2}^{2}$ (Dept. of food process Engineering, Sam Higginbottom Institute of Agriculture, Technology \& Sciences, India) \\ ${ }^{3}$ (Dept. of food process Engineering, Sam Higginbottom Institute of Agriculture, Technology \& Sciences, India) \\ ${ }^{4}$ (Dept. of food process Engineering, Sam Higginbottom Institute of Agriculture, Technology \& Sciences, India) \\ ${ }^{5}$ (Dept. of food Technology, Davanagere University, India)
}

\begin{abstract}
During recent years the wine industry has become increasingly dynamic due to competition among wine organisations worldwide. Many Indian wine organisations have implemented and maintained a Food Safety Managements System (FSMS). The Karnataka is one of the typical state of wine-manufacturing in the country. However, the impact of FSMSs on the effectiveness of work performance among wine organisations in the Karnataka. This study investigates the effectiveness of FSMS implementation to determine whether wine organisations consolidate the fundamental requirements of the FSMSs. 17 wine organisations situated in the Karnataka who are currently implementing FSMSs were chosen as the research sites. A group of participants who are implementing FSMSs from these wine organisations were selected as samples. A questionnaire based on the scale was used as an instrument for data collection. The findings of this study indicate that the majority of the wine organisations consolidate the fundamental requirements of FSMS. Management systems, prerequisite programs, HACCP, validation and verification, emergency preparedness and quality management are used as the main activities to measure the performance of FSMS. This study recommended that wine organisations should provide regular training to internal auditors and shop floor employees in order to enhance the effectiveness of FSMSs.
\end{abstract}

Keywords: Food Safety Management Systems (FSMSs), Quality Management, Impact, Effectiveness, Wine Industry.

\section{INTRODUCTION}

Food Safety and Standards Authority of India (FSSAI), FSS Act, 2006 Defines Food Safety Management System (FSMS) "means the adoption Good Manufacturing Practices, Good Hygienic Practices, Hazard Analysis and Critical Control Point and such other practices as may be specified by regulation, for the food business". Food Safety Management System enables the producers, processors, distributors, exporters, etc., of food products to utilize technical resources efficiently and in a cost effective manner in assuring food safety. An Evaluation of the Impact of Food Safety Management Systems (FSMS) within the Wine Industry is focuses on to validate the concept of FSMSs and to identify effective measures for the performance of these management systems. Firstly, the study defines various FSMSs, Secondly, the requirements of these various FSMSs are explored. It also covers a comparison, validation, application and the key factors affecting the FSMS. FSMSs are essential for any organisation producing food or beverages in order to provide credibility that the organisation can produce safe food. Whatever the product involved, a FSMS is designed to allow an organisation to guarantee food safety to consumer's as. The primary function of food safety standards is to define a set of requirements and associated systems of conformity assessment directed at regulatory compliance. Good FSMSs contain the following components: a Quality Management System (QMS) or adherence to the International Organisation for Standardisation (ISO); Good Manufacturing Practices (GMPs); and Hazard Critical Control Points (HACCP). The wine Organisations of Karnataka are spread out over the Southern and Northern Karnataka regions. In order for wine organisations to remain competitive and to satisfy customer requirements, wine organisations have to produce a wine that is of good quality and, more importantly, poses no harm to the consumer. Wine must therefore be produced under food safety requirements. In recent years many of the wine organisations situated in the Karnataka have successfully implemented and maintained Quality Management Systems (QMSs) and Food Safety Management Systems (FSMSs). The most recognised QMS implemented by cellars is FSMSs are: Hazard Critical Control Points (HACCP), Good Manufacturing Practices (GMP), Good Hygiene Practices (GHP) and ISO 22000:2005. The research is undertaken to identify the critical control points in the FSMS that is implemented at the selected wine organisations in the Karnataka. Various FSMSs are implemented at wine organisations, including the primary production cellars and secondary bottling plants. Although many wine organisations have implemented FSMSs over the past years, the impact of these 
FSMSs and how they reflect on the effectiveness of performance on the wine industry in the Karnataka, has however not been evaluated. It is therefore imperative that this study identifies whether these wine organisations conform to the fundamental requirements of the FSMSs, and to evaluate their performance in order to establish whether they meet the fundamental requirements of FSMSs.

\section{MATERIALS AND METHODS}

The research methods are commonly associated with quantitative and qualitative research paradigms. Qualitative research is usually employed for exploratory research and focuses on small respondent samples. It collects analyses and interprets data that cannot be meaningfully quantified. Quantitative research is usually adopted to collect, analyse and interpret data to describe the characteristics of large respondent samples. It is appropriate for collecting quantitative data and always employs a questionnaire survey as a research technique. The question of how to choose the appropriate research method is based on the nature of the data, the problem of the research, the location of the data, the obtaining of the data and for what intention the data is collected. The objective of this research is to determine the criteria that can be used to measure FSMSs effectively. For this reason a quantitative research design is applied. To reach the objectives of this research an explanatory research will be conducted whereby existing FSMSs was examined and compared in order to understand how each of the chosen respondents measure the performance of their FSMSs. The researcher poses a series of questions to willing participants: summarises the responses with percentages, frequency counts or more sophisticated indexes, and then draws inferences about a particular population from the responses of the sample. Surveys can be divided into two categories: the questionnaire and the interview. The aim is to establish what selected group of participants do, think or feel. Qualitative research data forms the core of this research. Data collection methods used in the survey falls within the context of a survey. Three types of research can be applied to research design, namely exploratory research, descriptive research and casual research. For the purposes of this research, descriptive research is chosen as the most appropriate approach in collecting and analysing the quantitative data to solve research problems.

\section{RESULTS AND DISCUSSION}

A total of 17 wine-producing organisations were selected as respondents of which only 16 organisations responded. A total of 92 responses from all of the participants of the 16 organisations where received by means of the completion of the questionnaires.

\subsection{Descriptive statistics for general questions on FSMS}

The data analysed in Figure was collected from the 92 respondents from the various wine-producing organisations participating in this research study.

This figure depicts the respondent's opinions on general statements about FSMS. It is of importance to note that the majority of the respondents all strongly agree on the general questions asked about the FSMS. All the organisations that participated in the survey already had a FSMS implemented and it was for this reason that most them strongly agreed. Most of the statements 1-6 had a positive response.

- GMP is a prerequisite for FSMS implementation (FS1)

- HACCP is implemented as foundation for the FSMS (FS2)

- Wine organisations review and improve their FSMS (FS3)

- Wine organisations measure the effectiveness and the performance of the FSMS (FS4 \&5)

- FSMS training programs are in place for staff members (FS6).

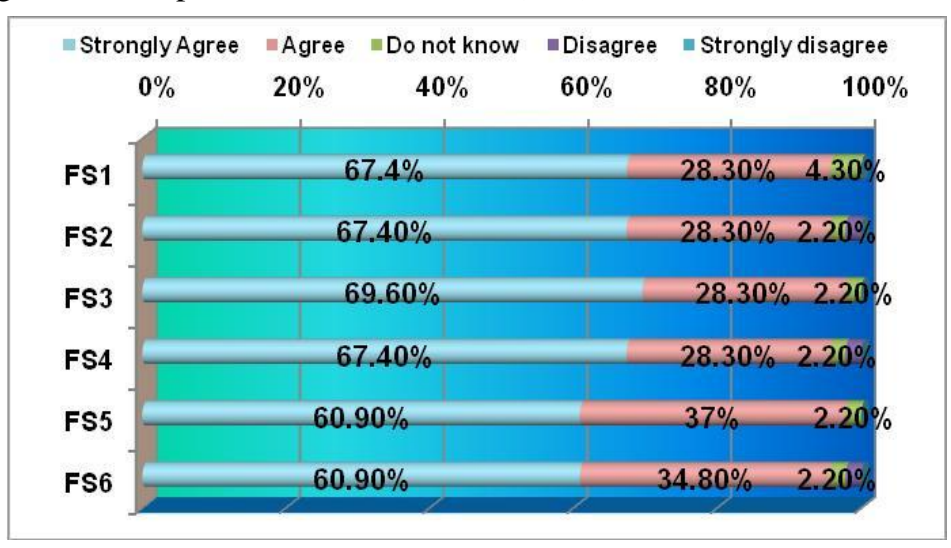

Fig 1: Responses regarding food safety questions 
3.2 Descriptive statistics for decision-making

According to Figure, the results from all 92 participants are positive. In particular, many responses are very positive, as above 90\% agree with the statements, such as DM7, DM12, DM13, DM14, DM15, DM17, DM19, DM20, DM22, DM23, and DM24. This indicates that the following areas are considered significant among these wine organisations:

- Management is committed to maintain FSMS (DM7);

- Corrective actions are used to improve the performance of FSMS (DM12);

- Certification audits are used to improve the performance of FSMS (DM13);

- Process control is applied to measure the performance of FSMS (DM14);

- Training programs for employees are in place to improve the performance of FSMS (DM15);

- Audit results are used to improve the performance of FSMS (DM17);

- FSMS is helpful to make product safer (DM19);

- FSMS is helpful in improving the quality of products (DM20);

- FSMS is helpful in improving customer satisfaction (DM22);

- Internal audits are used effectively to verify FSMS (DM23); and

- The analytical results of verification activities identified the need for updating or improving the FSMS (DM24).

- DM10, DM18 and DM21 indicates that FSMS has no positive implication on the volume of the returned products, statistical tools as measuring tool of FSMS and the reduction of waste.

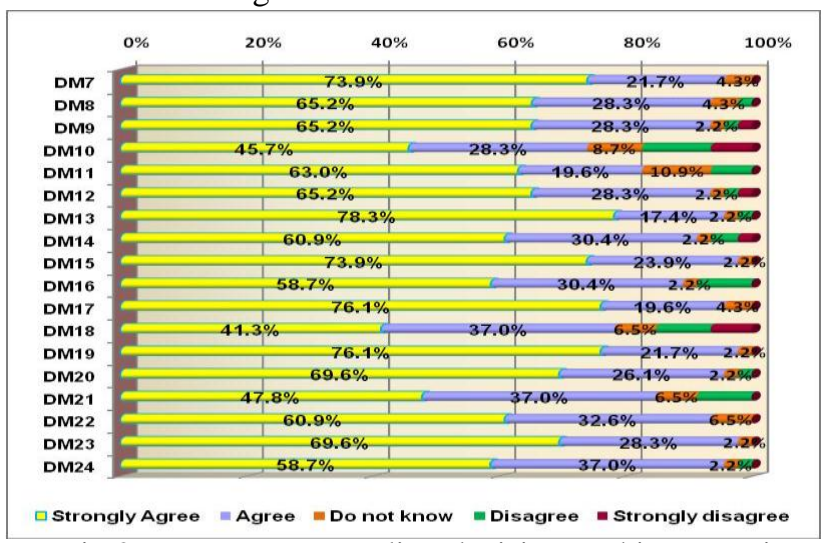

Fig 2: Responses regarding decision-making questions.

\section{CONCLUSION}

The importance of these FSMSs is to protect the consumer from any possible unsafe products produced. Over recent decades many organisations across the food spectrum have implemented a FSMS as their licence to trade. One major concern arising from the implementation of these FSMSs is the measuring of the performance measurement of the FSMS. Most organisations rely solely on the certifications audits as their only means of measuring the FSMS. The aim of this study was to evaluate the requirements of the FSMSs that need to be reported on to indicate effectiveness.

\section{Acknowledgements}

First of foremost, I would like to express my deepest sense of gratitude and thanks to Almighty God for his loving care and enabling me to accomplish this venture. And next he love, affection and patience of my family have been instrumental for me. Mere words cannot express my profound indebtness to my beloved Great mother Smt. GANGAMMA, my noble father Mr. KARIYAPPA.K, my sisters JYOTHI.K \& SHILPA.K YADAV my father in law JAYANNA.M and My lovely Nephew RITHVIKA YADAV.J.S (BELLI).

\section{REFERENCES}

[1] Aggeloginnopoulos, D. Drosinos, E. Athanasopoulos, P. 2006. Implementation of a quality management system (QMS) according to the ISO 9001 family in a Greek small-sized winery: a case study. Food Control, 18 (2007):1077:1085.

[2] Bas, M. Yuksel, M. Cavusoglu, T. 2007. Difficulties and barriers for the implementation of HACCP and food safety systems in food business in Turkey. Food Control, 18(2007):124-130.

[3] Christaki, T. \& Tzia, C. 2002. Quality and safety assurance in winemaking. Food Control, 13(2003):503-517.

[4] Henson, S., \& Humphrey, J. 2009. The Impacts of Private Food Safety Standards on the Food Chain and on Public Standard-Setting Processes. FAO Headquarters: Rome.

[5] International Organisation for Standardisation. (ISO 2005). Food Safety Management Systems - Requirements for any organisation in the food chain. (ISO, 22000).

[6] Mensah, L. \& Julien, D. 2011. Implementation of food safety management systems in the UK. Food Control, 22(1):1216-1225.

[7] Ropkins, K., A, Beck. 2000. Evaluation of worldwide approaches to the use of HACCP to control food safety. Trends in Food Science and Technology, 11(2000):10-21. 